\title{
ARMAZENAMENTO DE SEMENTES DE ORQUÍDEAS ${ }^{1}$
}

\author{
VERONICAALVAREZ-PARDO ${ }^{2}$, ALFREDO GUIFERREIRA $^{3}$
}

\begin{abstract}
RESUMO - Sementes de dezesseis espécies de orquídeas foram armazenadas a $5^{\circ} \mathrm{C}$ por até 42 meses, sendo verificada a viabilidade pelo teste de tetrazólio e de germinação. Houve perda da viabilidade conforme incremento no período de armazenamento. Por doze meses, a maioria das espécies estocadas a $5^{\circ} \mathrm{C}$, em dessecador com umidade relativa de $+6 \%$ de conteúdo de água, conservou a viabilidade próxima aos $100 \%$, com exceção da Cattleya labiata que apresentou queda de cerca de 50\% da viabilidade inicial. Cattleya intermedia, Encyclia pygmaea, E. odorantissima, Grobya sp., Oncidium flexuosum, Oncidium pumilum e um híbrido natural, Laeliocattleya conservaram, em geladeira, a viabilidade das sementes acima de $90 \%$, por até 24 meses. Para Cattleya intermédia, realizou-se armazenamento de sementes em tubos de polipropileno a $5,-18$ e a $25^{\circ} \mathrm{C}$, em dessecador ou condições ambientais sem controle de umidade. Em condições de laboratório houve perda quase total da viabilidade das sementes. A estocagem em geladeira a $5^{\circ} \mathrm{C}$ ou em "freezer" a $-18^{\circ} \mathrm{C}$ fornece condições adequadas para conservar a viabilidade de sementes de orquídeas. Com essa mesma espécie, as sementes foram armazenadas a $-18^{\circ} \mathrm{C}$ durante 24 semanas, sendo testada semanalmente sua viabilidade. Para tais avaliações, as sementes eram transferidas diretamente de $-18^{\circ} \mathrm{C}$ para temperatura ambiente de laboratório $\left(25^{\circ} \mathrm{C}\right)$ ou indiretamente, por uma hora a $5^{\circ} \mathrm{C}$, depois para temperatura ambiente por uma hora. A transferência indireta foi mais eficiente na conservação da viabilidade.
\end{abstract}

Termos para indexação: conservação, tetrazólio, germinação, viabilidade.

\section{ORCHID SEED STORAGE}

ABSTRACT - Orchid seeds of sixteen Brazilian Southern species were stored at $5^{\circ} \mathrm{C}$ up to 42 months, when the viability was tested by the tetrazolium or germination performance. There was loss of viability when storage was extended. For one year, the viability of the majority of the seeds stored at $5{ }^{\circ} \mathrm{C}$ in a dessecator with $\pm 6 \%$ of water content was preserved near to $100 \%$, except for Cattleya labiada which lost around $50 \%$ of its seeds' viability. Cattleya intermedia, Encyclia pigmaea, E. odorantissima, Grobya sp., Oncidium flexuosum, O. pumilum and one natural hybrid of Laeliocattleya maintained seed viability of over $90 \%$ to 24 months at $5^{\circ} \mathrm{C}$. Cattleya intermedia seeds were stored in polipropylene tubes at $5^{\circ} \mathrm{C}$ or $-18^{\circ} \mathrm{C}$ and either $25^{\circ} \mathrm{C}$ in a dessecator or in open flasks under laboratory environmental conditions. Most the seeds of this species died under laboratory conditions in one year. Storage at $5^{\circ} \mathrm{C}$ or in a freezer $\left(-18^{\circ} \mathrm{C}\right)$ were the best conditions to maintain the orchid seed viability. With this same species the seeds were stored at $-18^{\circ} \mathrm{C}$ for 24 weeks, and the viability tested weekly.. The seeds were transferred directly from this temperature to $25^{\circ} \mathrm{C}$ or indirectly, for one hour at $5^{\circ} \mathrm{C}$, and then to the environmental temperature in the laboratory $\left(25^{\circ} \mathrm{C}\right)$. The indirect transfer preserved viability more efficiently.

Index terms: conservation, tetrazolium, germination, viability

\footnotetext{
${ }^{1}$ Submetido em 16/09/2004. Aceito para publicação em 28/03/2005. Parte da tese de doutorado apresentada para o Programa de Pós-graduação em Botânica/UFRGS, pelo primeiro autor;

${ }^{2}$ Eng. Agrônomo, doutora. Professora substituta do Departamento de
}

Botânica da Universidade Federal do Rio Grande do Sul (UFRGS);

${ }^{3}$ Professor titular do Departamento de Botânica da UFRGS e bolsista do CNPq. Caixa postal 15015, Porto Alegre, RS, Brasil. CEP 91501-970, ferreira@unb.br 


\section{INTRODUÇÃO}

O procedimento de armazenamento utilizado na conservação de sementes tem sido escassamente abordado para armazenamento de sementes de orquídeas (Seaton e Hailes, 1989; Jesup, 1996).

Sugere-se que as sementes de orquídeas apresentam comportamento semelhante aos das sementes ortodoxas (Pritchard e Seaton, 1993; Pritchard et al., 1999). E, como tais, são fisiologicamente afetadas pelas condições de armazenamento, incluindo as de criopreservação (Pritchard e Prendergast, 1989).

A vitalidade dessas sementes pode ser favorecida com a adequação do período de coleta dos frutos e com as reduções do teor de água das sementes, da temperatura e da pressão de oxigênio na atmosfera de armazenamento (Seaton e Pritchard, 1990, Thornhill e Koopowitz, 1992, Mello, 2000).

O uso de bancos de sementes, para conservação ex situ de germoplasmas de orquídeas depende de disponibilidade de conhecimentos, capazes de permitir a definição de temperaturas e graus de umidade ao armazenamento (Pritchard e Seaton, 1993; Koopowitz, 1996).

O objetivo deste estudo foi verificar o comportamento germinativo e de viabilidade de sementes de orquídeas nativas durante o armazenamento.

\section{MATERIAL E MÉTODOS}

Os experimentos foram conduzidos no Laboratório de
Fisiologia Vegetal do Departamento de Botânica da de Universidade Federal do Rio Grande do Sul (UFRGS - Porto Alegre, RS).

Frutos com sementes de Bifrenaria inodora Lindl., Cattleya bicolor Lindl., Cattleya intermedia R.Grah (misturas), Cattleya intermedia var. pallida Lindl., Cattleya labiata Lindl., Encyclia pygmaea (Hook.) Dressler, Encyclia odorantissima Schltr., Epidendrum fulgens A. Brongn., Grobya sp. Lindl., Laelia purpurata Lindl. Paxt., Laeliocattleya Rolfe, Maxillaria picta Hook., Oncidium enderianum Hort., Oncidium flexsuosum Sims, Oncidium pumilum Lindl. Pleurothallis glumacea Lindl. foram coletados nas regiões leste e litoral norte do Rio Grande do Sul (Tabela 1).

As superfícies dos frutos (cápsulas fechadas prédeiscentes) foram lavadas com água e detergente neutro, recebendo posteriormente, limpeza com álcool (70\%). A seguir, as cápsulas foram colocadas em dessecadores com sílica gel até a deiscência. Após, as sementes foram isoladas e colocadas em envelopes de papel Kraft, mantidas nos dessecadores contendo cloreto de cálcio hexahidratado, durante 10 dias (Thompson, 1980; Seaton e Pritchard, 1990).

A viabilidade foi avaliada pelos testes de tetrazólio e teste de germinação. No teste de tetrazólio, as sementes previamente embebidas durante 24 horas em água destilada, foram imersas em solução aquosa (1\%) de sal de tetrazólio (cloreto de 2,3,5 trifenil tetrazólio) e mantidas na ausência de luz a $30^{\circ} \mathrm{C}$, durante 24 horas (Singh, 1981; Jordão et al., 1988). A contagem foi realizada ao microscópio estereoscópico, considerando-se viáveis as sementes portadoras de embriões coloridos de

TABELA 1. Procedências e épocas de coleta dos frutos das orquídeas estudadas

\begin{tabular}{lcc}
\hline \multicolumn{1}{c}{ Espécies } & Procedências $^{\mathbf{a}}$ & Épocas de coleta dos frutos $^{\mathbf{b}}$ \\
\hline Bifrenaria inodora Lindl. & Terra de Areia & Maio/99 \\
Cattleya bicolor Lindl. & Terra de Areia & Fevereiro/99 \\
Cattleya intermedia var. pallida Lindl. & Terra de Areia & Abril/99 \\
Cattleya intermedia R. Grah. & Montenegro & Maio/00 \\
Cattleya labiata Lindl. & Terra de Areia & Fevereiro/99 \\
Encyclia odorantissima Hook & Terra de Areia & Agosto/99 \\
Encyclia pygmaea Hook. & Terra de Areia & Março/99 \\
Epidendrum fulgens A. Brongn & Viamão & Agosto/00 \\
Grobya sp. R. Br. & São Leopoldo & Novembro/99 \\
Laelia purpurata Lidl. Paxt & Terra de Areia, Montenegro & Agosto-Outubro/99; Abril/00 \\
Laeliocattleya Rolfe & Terra de Areia & Outubro/98 \\
Maxillaria picta Hook. & Viamão & Agosto/99 \\
Oncidium pumilum Lindl. & Terra de Areia & Março/99 \\
Oncidium enderianum Hort & Terra de Areia & Agosto/99 \\
Oncidium flexuosum Sims & Terra de Areia & Abril/00 \\
Pleurothallis glumacea Lindl. & Viamão & Março/00 \\
\hline
\end{tabular}

a - Municípios na Depressão Central ou Litoral-norte do Estado de Rio Grande do Sul

b (-) Testes não efetuados. 
vermelho (Lauzer et al., 1994).

O teste de germinação foi realizado em meio Knudson C (Knudson, 1946) adicionado de micronutrientes (Arditti et al., 1982) e suplementado com de tiamina $\left(0,05 \mathrm{mg} . \mathrm{L}^{-1}\right)$, de ácido nicotínico $\left(0,05 \mathrm{mg} . \mathrm{L}^{-1}\right)$, de sacarose $\left(20 \mathrm{~g} . \mathrm{L}^{-1}\right)$ e de agar $\left(6 \mathrm{~g} . \mathrm{L}^{-1}\right)$ com o $\mathrm{pH}$ do meio com $\mathrm{NaOH}$ para 5,7. O substrato, recoberto com filme de alumínio em camada dupla, foi autoclavado a $120^{\circ} \mathrm{C}$ por 20 minutos e colocado em tubos de ensaio $(10 \mathrm{~mL}$ por tubo de $20 \mathrm{x} 1,5 \mathrm{~cm})$ que foram inclinados, ainda quentes, permitindo incrementar a superfície de semeadura.

Previamente à semeadura, as sementes foram desinfestadas com gás formol por uma hora (Alvarez-Pardo et al., 2001), em câmara de fluxo laminar. Depois, o material foi transferido para sala de crescimento à temperatura de $25+5^{\circ} \mathrm{C}$ com fotoperíodo de 16 horas (luz branca de $\left.30 \mu \mathrm{mol} \cdot \mathrm{m}^{-2} \cdot \mathrm{s}^{-1}\right)$, por 30 dias. Após, as sementes foram examinadas ao microscópio estereoscópico e aquelas que apresentavam embriões expandidos e massa celular de coloração verde (estágio 1) foram consideradas germinadas, segundo as definições de Seaton e Hailes (1989) e Milaneze (1997).

Ensaio 1. Armazenamento de sementes a $5^{\circ} \mathrm{C}$.

As sementes das 16 espécies de orquídeas foram armazenadas até 42 meses com um teor de água próximo de 6\% (Pritchard e Seaton, 1993), em tubos de polipropileno (capacidade $1,5 \mathrm{~mL}$ ) contendo fibras de algodão no espaço não ocupado pelas sementes. Os tubos foram colocados dentro de frascos herméticos de vidro $(20 \mathrm{~mL})$ e mantidos a $5+1^{\circ} \mathrm{C}$

A viabilidade expressada em percentagem foi verificada semestralmente, empregando-se os testes de tetrazólio e germinação, ambos realizados com quatro repetições de 10mg de sementes por espécie. Estudo de Correlação foram realizados com as médias das repetições entre os testes de viabilidade, usando-se o programa estatístico SSPS-10.

Ensaio 2. Condições de armazenamento das sementes de Cattleya intermedia

As sementes de Cattleya intermedia, obtidas pela reunião de amostras provenientes de duas regiões do estado do Rio Grande do Sul, apresentaram teor de água inicial de 6\%, segundo a metodologia descrita por Pritchard e Seaton (1993).

As sementes armazenadas durante 24 meses, nas condições indicadas na Tabela 2, foram semestralmente avaliadas pelos testes de tetrazólio e de germinação, ambos realizados com três repetições e expressos em percentagem. Foi utilizado delineamento inteiramente casualisado em esquema fatorial de 6 x 5 (condições de armazenamento x períodos de armazenamento). Os dados em percentagem foram transformados em $\operatorname{arcsen}(\mathrm{x}+10)^{1 / 2}$, submetidos à análise de variância e realizado o teste de comparação de médias por Tukey ( $\mathrm{p} £ 5$ ), com o programa estatístico SSPS-10.

Ensaio 3. Curtas interrupções nas condições de armazenamento.

Foram utilizadas sementes de Cattleya intermedia, que apresentaram viabilidade inicial de $99 \pm 1 \%$ pelo teste de tetrazólio, armazenadas a $-18^{\circ} \mathrm{C}$ durante 24 semanas, o qual foi semanalmente interrompido pela transferência das sementes para ambiente de laboratório $\left(25+5^{\circ} \mathrm{C}\right)$, utilizando-se os seguintes procedimentos:

Tratamento A (indireto): transferência das sementes para $5^{\circ} \mathrm{C}$ por uma hora, seguida de permanência a $25 \pm 5^{\circ} \mathrm{C}$ por uma hora e imediato retorno a condição de $-18^{\circ} \mathrm{C}$;

Tratamento B (direto): transferência para ambiente a $25 \pm 5^{\circ} \mathrm{C}$ por uma hora e imediato retorno à condição inicial de $-18^{\circ} \mathrm{C}$.

As subamostras retiradas semanalmente eram avaliadas pelos testes de germinação e de tetrazólio, com três repetições e expressos em porcentagem. Foi utilizado delineamento inteiramente casualizado em fatorial 2 x 20 (tratamentos x

TABELA 2. Armazenamento de sementes de Cattleya intermedia em diferentes condições por 24 meses

\begin{tabular}{clc}
\hline Tratamntos & \multicolumn{1}{c}{ Acondicionamento } & Temperatura $\left({ }^{\circ} \mathrm{C}\right)$ \\
\hline T1 & $\begin{array}{l}\text { tubos de polipropileno herméticos, contendo fibras de algodão no espaço não } \\
\text { ocupado pelas sementes. } \\
\text { tubos de polipropileno herméticos, contendo fibras de algodão no espaço não } \\
\text { ocupado pelas sementes. }\end{array}$ & -18 \\
T2 & $\begin{array}{l}\text { tubos de polipropileno hermético, contendo fibra de algodão no espaço não } \\
\text { ocupado pelas sementes e mantidos no interior de um desseca dor. }\end{array}$ & $25 \pm 5$ \\
T4 & $\begin{array}{l}\text { tubos de polipropileno herméticos, contendo fibras de algodão no espaço não } \\
\text { ocupado pelas sementes. }\end{array}$ & $25 \pm 5$ \\
T5 & $\begin{array}{l}\text { Em envelopes de papel de seda } \\
\text { T6 }\end{array}$ & Em envelopes de papel de seda no interior de um dessecador. \\
\hline
\end{tabular}


momentos de transferência). Os dados em percentagem foram transformados em $\operatorname{arcsen}(\mathrm{x}+10)^{1 / 2}$, submetidos à análise de variância, seguido de análise de regressão (programa SSPS$10)$.

\section{RESULTADOS E DISCUSSÃO}

Obter frutos com sementes com boa qualidade fisiológica requer cuidados e atenção, não podem ser coletados muito verdes, pois as sementes podem não ter atingindo a maturidade, nem colocadas em condições inadequadas como sacos plásticos fechados. Altas temperaturas pós-coleta $\left({ }^{3} 30^{\circ} \mathrm{C}\right)$ podem prejudicar a viabilidade das sementes, assim como coletas em casa de vegetação, onde pode haver prevalência de sementes sem embriões pela falta do polinizador natural. As cápsulas, em geral, apresentam uma coloração amarelada antes da abertura das fendas de maturação. Entretanto, em expedições de coleta a campo, esta operação se torna difícil (Mello, 2000), preferindo-se realizar coletas unicamente de cápsulas no início da deiscência (Thompson, 1980; Pritchard e Seaton, 1993). Para completar a maturação, deve-se colocar os frutos em dessecadores com sílica gel ou cloreto de cálcio, até que ocorra uma abertura completa. É imprescindível diminuir o teor de água das sementes para depois armazená-las (Seaton e Pritchard, 1990; Pritchard et al., 1999).

Houve perda da viabilidade das sementes (Ensaio 1) com o avanço de período de armazenamento em todas espécies estudadas (Tabela 3), detectadas tanto pelo teste de germinação como de tetrazólio, que apresentaram alta correlação. Por

TABELA 3. Ensaio 1: dados obtidos nos testes de tetrazólio (TZ) e de germinação (G) de sementes de orquídeas armazenadas a $5^{\circ} \mathrm{C}$ durante 42 meses

\begin{tabular}{|c|c|c|c|c|c|c|c|c|c|c|}
\hline \multirow{2}{*}{ Espécies } & \multicolumn{4}{|l|}{ Testes } & \multicolumn{6}{|c|}{ Meses } \\
\hline & $\%$ & 0 & 6 & 12 & 18 & 24 & 30 & 36 & 42 & Valores de $\mathbf{R}^{\mathbf{a}}$ \\
\hline \multirow[t]{2}{*}{ Epidendrum fulgens } & $\mathrm{TZ}$ & 83 & 84 & 83 & 57 & 52 & $-{ }^{b}$ & - & - & 0,896 \\
\hline & $\mathrm{G}$ & 89 & 80 & 68 & 57 & 43 & - & - & - & \\
\hline \multirow[t]{2}{*}{ Grobya sp. } & $\mathrm{TZ}$ & 94 & 86 & 83 & 72 & 73 & - & - & - & 0,876 \\
\hline & $\mathrm{G}$ & 92 & 90 & 71 & 66 & 48 & - & - & - & \\
\hline \multirow[t]{2}{*}{ Cattleya Intermedia } & $\mathrm{TZ}$ & 99 & 99 & 96 & 96 & 92 & - & - & - & 0,850 \\
\hline & $\mathrm{G}$ & 99 & 98 & 96 & 95 & 95 & - & - & - & \\
\hline \multirow{2}{*}{ Oncidium flexsuosum } & $\mathrm{TZ}$ & 94 & 93 & 91 & 88 & 90 & - & - & - & 0,852 \\
\hline & $\mathrm{G}$ & 95 & 96 & 92 & 89 & 87 & - & - & - & \\
\hline \multirow[t]{2}{*}{ Pleurothallis glumacea } & $\mathrm{TZ}$ & 100 & 98 & 48 & 35 & 36 & - & - & - & 0,982 \\
\hline & $\mathrm{G}$ & 99 & 99 & 55 & 22 & 34 & - & - & - & \\
\hline \multirow[t]{2}{*}{ Oncidium enderianum } & $\mathrm{TZ}$ & 100 & 97 & 91 & 75 & 63 & 34 & - & - & 0,998 \\
\hline & $\mathrm{G}$ & 100 & 98 & 95 & 71 & 56 & 21 & - & - & \\
\hline \multirow[t]{2}{*}{ Maxillaria picta } & $\mathrm{TZ}$ & 98 & 98 & 91 & 88 & 73 & 1 & - & - & 0,975 \\
\hline & G & 94 & 94 & 82 & 81 & 49 & 0 & - & - & \\
\hline \multirow[t]{2}{*}{ Laelia purpurata } & $\mathrm{TZ}$ & 95 & 94 & 93 & 77 & 63 & 41 & - & - & 0,994 \\
\hline & $\mathrm{G}$ & 95 & 93 & 90 & 76 & 56 & 40 & - & - & \\
\hline \multirow[t]{2}{*}{ Bifrenaria inodora } & $\mathrm{TZ}$ & 98 & 92 & 91 & 69 & 54 & 19 & 9 & - & 0,997 \\
\hline & $\mathrm{G}$ & 100 & 99 & 92 & 64 & 49 & 3 & 0 & - & \\
\hline \multirow[t]{2}{*}{ Encyclia pygmaea } & $\mathrm{TZ}$ & 100 & 99 & 96 & 91 & 91 & 89 & 84 & - & 0,995 \\
\hline & $\mathrm{G}$ & 100 & 99 & 95 & 86 & 86 & 84 & 78 & - & \\
\hline \multirow[t]{2}{*}{ Oncidium pumilum } & $\mathrm{TZ}$ & 99 & 94 & 88 & 86 & 86 & 89 & 75 & - & 0,929 \\
\hline & $\mathrm{G}$ & 97 & 86 & 90 & 83 & 81 & 83 & 63 & - & \\
\hline \multirow[t]{2}{*}{ Cattleya iIntermedia pallida } & $\mathrm{TZ}$ & 99 & 100 & 100 & 99 & 94 & 69 & 54 & - & 0,992 \\
\hline & $\mathrm{G}$ & 100 & 100 & 99 & 100 & 99 & 70 & 48 & - & \\
\hline \multirow[t]{2}{*}{ Cattleya bicolor } & $\mathrm{TZ}$ & 100 & 99 & 84 & 68 & 52 & 41 & 14 & - & 0,972 \\
\hline & $\mathrm{G}$ & 99 & 99 & 79 & 68 & 61 & 20 & 6 & - & \\
\hline \multirow[t]{2}{*}{ Cattleya labiata } & $\mathrm{TZ}$ & 63 & 58 & 29 & 14 & 9 & 2 & 0 & - & 0,996 \\
\hline & $\mathrm{G}$ & 61 & 61 & 24 & 14 & 6 & 1 & 0 & - & \\
\hline \multirow[t]{2}{*}{ Encyclia odorantissima } & $\mathrm{TZ}$ & 100 & 99 & 99 & 93 & 92 & 84 & 74 & - & 0,989 \\
\hline & G & 99 & 99 & 97 & 91 & 94 & 82 & 70 & - & \\
\hline \multirow[t]{2}{*}{ Laeliocattleya } & $\mathrm{TZ}$ & 100 & 100 & 100 & 98 & 100 & 74 & 72 & 43 & 0,990 \\
\hline & $\mathrm{G}$ & 100 & 99 & 100 & 97 & 98 & 67 & 57 & 35 & \\
\hline
\end{tabular}

${ }^{a}$ Valores de correlação entre os dados dos testes de tetrazólio e de germinação.

${ }^{\text {b }}$-) Testes não efetuados. 
insuficiência de material, em algumas espécies os testes foram efetuados até 24 ou 30 meses. Em outras espécies, como Maxillaria picta e Cattleya labiata, que em 30 meses, perderam quase completamente a viabilidade.

Existiu interação significativa entre as condições e os períodos de armazenamento das sementes de $C$. intermédia
(Ensaio 2). Nas condições de baixa temperatura $\left(\mathrm{T}_{1}=5^{\circ} \mathrm{C}\right.$ ou $\mathrm{T}_{2}=-18^{\circ} \mathrm{C}$ ), as sementes dessa espécie não alteraram a viabilidade durante 24 meses de armazenamento (Figura $1 \mathrm{~A} \mathrm{e}$ B). Até seis meses de armazenamento $\mathrm{T}_{1}, \mathrm{~T}_{2}, \mathrm{~T}_{3}$ e $\mathrm{T}_{6}$, mantiveram-se estatisticamente iguais (Figura 1A e B). As sementes armazenadas em condições ambientais fora do

$1 \mathbf{A}$

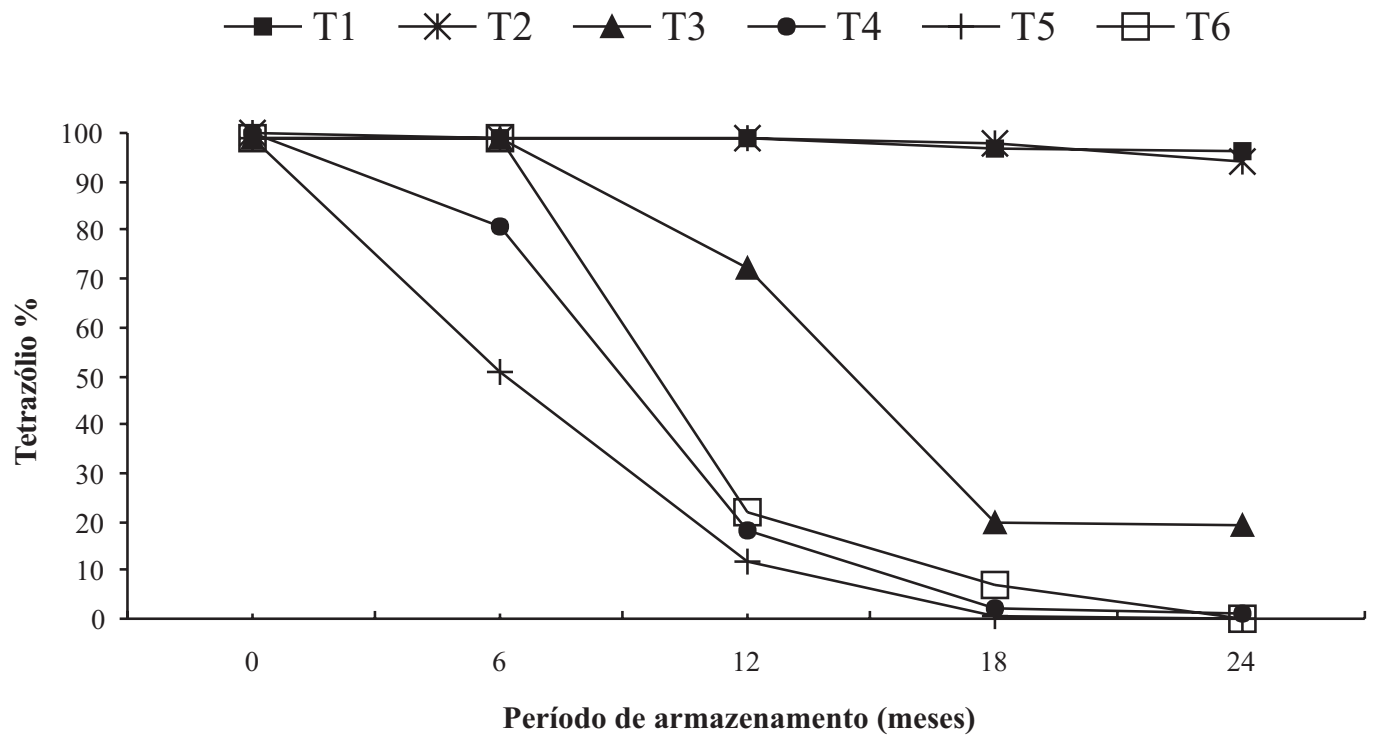

$1 B$

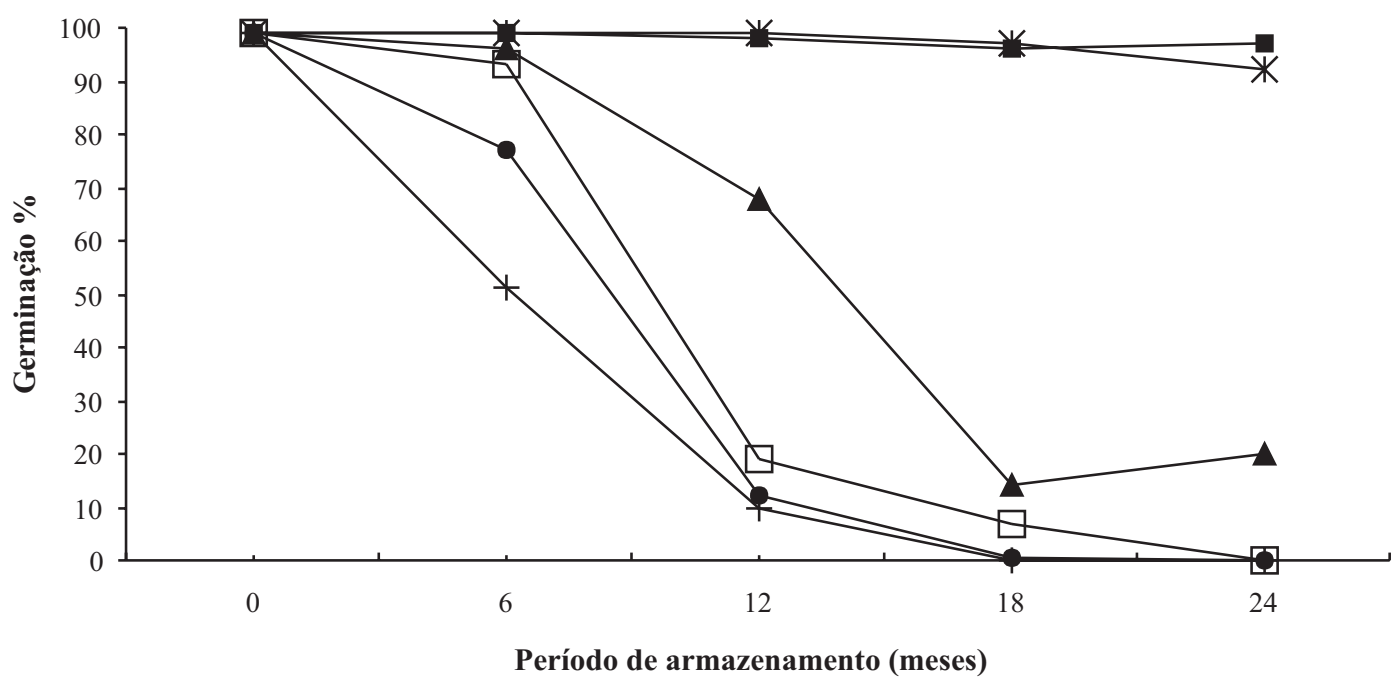

FIGURA 1. Ensaio 2: dados obtidos nos testes de tetrazólio (1A) e de germinação (1B) para as condições de armazenamento adotadas durante 0 armazenamento $\left(\mathrm{T} 1=\mathrm{em}\right.$ tubos de polipropileno $(1,5 \mathrm{~mL})$ a $5^{\circ} \mathrm{C} ; \mathrm{T} 2=\mathrm{em}$ tubos $\mathrm{a}-18^{\circ} \mathrm{C} ; \mathrm{T} 3=\mathrm{em}$ tubos em dessecador a $25^{\circ} \mathrm{C}$; $\mathrm{T} 4=\mathrm{em}$ tubos sem dessecador a $25^{\circ} \mathrm{C}$; $\mathrm{T} 5=\mathrm{em}$ envelope de papel de seda sem dessecador a $25^{\circ} \mathrm{C}$; T6=em envelope de papel com dessecador a $25^{\circ} \mathrm{C}$ ) de 24 meses das sementes de Cattleya intermedia. 
dessecador $\left(\mathrm{T}_{4}=\right.$ tubo de polipropileno e $\mathrm{T}_{5}=$ em papel de seda) mostraram perda da viabilidade já aos seis meses de estocagem, perdendo completamente a viabilidade aos 18 meses. Efeito similar foi observado por Limartha (1975) para sementes de Phalaenopsis amabilis e Dendrobium phalaenopsis, que perderam $30 \%$ da viabilidade em 20 dias a temperatura de $25-28^{\circ} \mathrm{C}$. Mello (2000) comprovou a perda da viabilidade de sementes de várias espécies de orquídeas do Cerrado brasileiro, armazenadas a $25^{\circ} \mathrm{C}$. Assim, o controle da temperatura e do teor de água nas sementes interfere na conservação das sementes de várias espécies de orquídeas.

Houve efeito significativo entre os períodos de armazenamento e os procedimentos de transferência (Ensaio $3)$, indicando que o efeito dos tratamentos dos lotes A e B estavam na dependência dos ciclos de armazenamento das sementes de Cattleya intermedia, a partir da quinta semana de avaliação com os métodos direto e indireto (Figura 2) Segundo o teste de tetrazólio (Figura 2A), a perda da

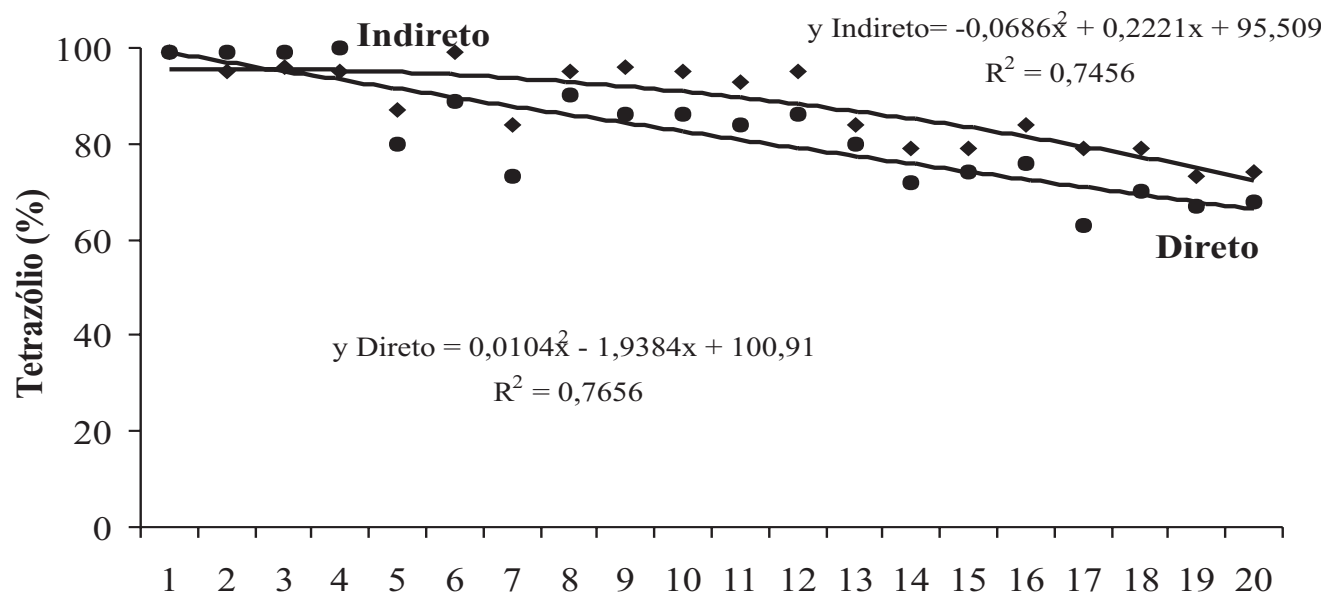

Período de armazenamento (semanas)

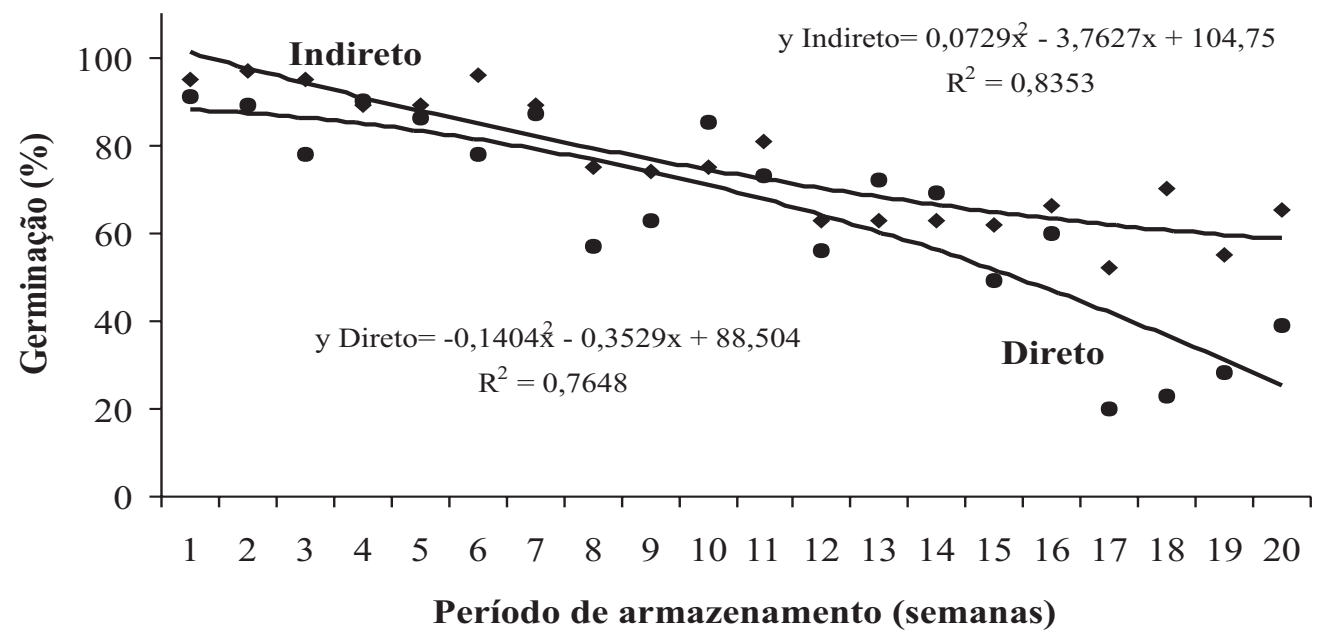

FIGURA 2. Ensaio 3: dados dos testes de tetrazólio (2A) e germinação (2B), obtidos para os tratamentos de lote direto $\left(\right.$ de $-18^{\circ} \mathrm{C}$ para $\left.25^{\circ} \mathrm{C}\right)$ e lote indireto $\left(\mathrm{de}-18^{\circ} \mathrm{C}\right.$; para $5^{\circ} \mathrm{C}$; para $\left.25^{\circ} \mathrm{C}\right)$, aplicados em sementes de Cattleya intermedia. 
viabilidade, após os vinte ciclos avaliados, foi de $20 \%$ em ambos os lotes (indireto e direto) e de acordo com o teste de germinação (Figura 2B), perdeu-se de 30 a $50 \%$, para estes dois lotes. Sabe-se que quanto mais frio e maior a diferença de temperatura com ambiente, maior é a condensação de umidade sobre o corpo resfriado. Assim, transferir as sementes diretamente de $-18^{\circ} \mathrm{C}$ para a temperatura ambiente, deve condensar mais umidade sobre essas. Como foi ressaltado anteriormente, o controle da umidade relativa e do teor de água nas sementes influi na viabilidade das mesmas, e isto pode ter prejudicado na germinabilidade. Não se mediu o grau de absorção de água pelas sementes após as transferências. Desta forma, se houver necessidade de várias subamostras de sementes ao longo do tempo, na estocagem inicial, devese dividir o material e as sobras não devem voltar para as condições de baixas temperaturas de armazenamento $\left(5^{\circ} \mathrm{C}\right.$ ou $-18^{\circ} \mathrm{C}$ ).

\section{CONCLUSÕES}

Há perda da viabilidade das sementes conforme aumenta o período de armazenamento, nas dezesseis espécies estudadas.

A conservação de sementes de Cattleya intermedia é favorecida por temperaturas ambientais de $5 \mathrm{e}-18^{\circ} \mathrm{C}$.

Há perda de viabilidade com as mudanças de temperatura de $-18^{\circ} \mathrm{C}$ para $25^{\circ} \mathrm{C}$ nos lotes A (indireto) e B (direto) de sementes de C.intermedia, ao final dos vinte ciclos de armazenamento. $\mathrm{O}$ método indireto mostrou menor perda de viabilidade ao longo dos vinte ciclos analisados.

\section{REFERÊNCIAS}

ALVAREZ-PARDO, V; SOUZA, F.L. FERREIRA, A.G. Desinfestação de sementes de orquídeas. In: CONGRESSO NACIONAL DE FISIOLOGIA VEGETAL, 2001, Ilhéus. Anais... Ilhéus: SBFV, 2001. CD-ROM.

ARDitTI, J.; CLEMENTS, G.; FAST, G.; HADLEY, G.; NISHIMURA, G.; ERNST, R. Orchid seed germination and seedling culture - A manual. In: ARDITTI, J. (Ed.) Orchid biology: reviews and perspectives II. New York: Cornell University Press. 1982. p. 244-370

JESUP, A.L. Ex situ conservation. In: HÁGSATER E.; DUMONT, V. (Eds.) Orchids. Cambridge: IUCN Publications Service Unit. 1996, p. 23-27.

JORDÃO, L.R.; LOPES, V.B.; TAKAKI, M.. Selection of viable seeds in Hormidium coriaceum Ldl. (Orchidaceae) by density separation. Seed Science and Technology, Zürich, v.16, p. 515-19. 1988.

KNUDSON. L. A new nutrient solution for the germination of orchid seed. American Orchid Society Bulletin, West Palm Beach, v.15, p. 214-17, 1946.

KOOPOWITZ, H. Propagation for genetic diversity. In: HAGSATER, E.; DUMONT, V. (Ed.) Orchids. Cambridge: IUCN Publications Service Unit, 1996. p. 27-32.

LAUZER, D.; ST-ARNAUD, M.; BARABÉ, D. Tetrazolium staning and in vitro germination of mature seeds of Cypripedium acaule (Orchidaceae). Lindleyana, Palm Beach, v.9, n.3, p. 197-204, 1994.

LIMARTHA, I. Influence of media and seed storage time on orchid germination. Hawaii Orchid Journal, v. 4, p.6-8, 1975.

MELlO, C.M.C. Conservação de sementes de orquídeas do Cerrado. 2000, 48 p. Dissertação (Mestrado em Biologia). Universidade de Brasília, Brasília, 2000.

MILANEZE, M.A. Estudos em orquídeas nativas do Brasil. Morfologia de sementes e cultivo assimbiótico. 1997, 241f. Tese (Doutorado em Biologia Vegetal) - Instituto de Biociências do Campus de Rio Claro, Universidade Estadual Paulista, Rio Claro, 1997.

PRITCHARD, H.W.; PREDERGAST, F.G. Factors influencing the germination and storage characteristics of orchid pollen. In: PRITCHARD, H.W. (Ed.) Modern methods in orchid conservation: the role of physiology, ecology and management. Cambridge: University Press, 1989. p.1-16.

PRITCHARD, H.W.; SEATON, P.T. Orchids seed storage: Historical perspective current status and future prospects for long-term conservation. Selbyana, Sarasota, v.14, p. 89-104. 1993.

PRITCHARD, H.W.; POINTER, L.C.A.; SEATON, T.P. Interspecific variation in orchid seed longevity in relation to ultra-dry storage and cryopreservation. Lindleyana, Palm Beach, v.14, n. 2, p. 92101, 1999.

SEATON, P.; PRITCHARD, H. The do's and dont's of orchid seed storage. The Orchid Review, v. 98, p. 172-74, 1990.

SEATON, P.T.; HAILES, N.S.J. 1989. Effect of temperature and moisture content on the viability of Cattleya aurantiaca seed. In: PRITCHARD, H.W. (Ed.) Modern methods in orchid conservation: the role of physiology, ecology and management. Cambridge: University Press. 1989, p.17-29.

SINGH, F. Differential staining of orchid seeds for viability testing. American Orchid Society Bulletin, West Palm Beach, v. 50, p. 416-18, 1981.

THOMPSON, P.A. Orchids from seed. London: RBGK/ McCorquodale Printer Ltd, 1980. 29 p.

THORNHILL, A.; KOOPOWITZ, H. Viability of Disa uniflora (Orchidaceae) seeds under variable storage conditions: is orchid gene-banking possible?. Biological Conservation, Essex, v.1, p. 21-27, 1992. 